\title{
Determination of lead chelated with ethylenediaminetetra-acetic acid in blood after precipitation of protein with perchloric acid
}

\author{
A. A. CERNIK \\ Medical Branch, H.M. Factory Inspectorate, Department of Employment and \\ Productivity, London
}

\begin{abstract}
Cernik, A. A. (1970). Brit. J. industr. Med., 27, 40-42. Determination of lead chelated with ethylenediaminetetra-acetic acid in blood after precipitation of protein with perchloric acid. A method is described for the determination of lead in whole blood containing ethylenediaminetetra-acetic acid. Proteins were precipitated by $2.0 \mathrm{M}$ perchloric acid. The ionized lead in the supernatant was chelated with ammonium pyrrolidine dithiocarbamate and was extracted with xylene. The method agreed well with a dry ashing technique $(30$ samples,

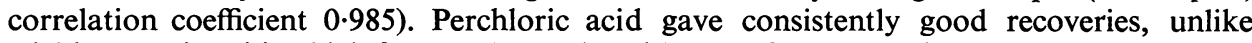
trichloroacetic acid, which frequently produced losses of up to $15 \%$.
\end{abstract}

In many methods for determining lead in blood the organic matter has to be destroyed, to yield ionic lead. This involves a time-consuming wet or dry oxidation.

Berman (1964) used a rapid and simple method that extracted lead from the supernatant, after precipitating the protein of blood samples with trichloroacetic acid, followed by an atomic absorption spectrophotometric determination. The results on heparinized blood compared well with a dithizone colorimetric method, but ethylenediaminetetra-acetic acid (EDTA) was reported to interfere. This casts doubt on the use of the method on blood from subjects under treatment with EDTA for lead poisoning. The present paper gives a satisfactory method for lead in blood in the presence of EDTA.

Slavin and Sprague (1964) used 8.0\% trichloroacetic acid precipitation with heparinized blood to extract the lead from thesupernatant with ammonium pyrrolidine dithiocarbamate and methyl-iso-butylketone. They observed that some lead might be lost in the precipitate.

Selander and Cramér (1968b) found good agreement between a modification of Berman's technique and a wet ashing procedure and a spectral analysis method. Heparinized blood was used in all cases except five samples from patients who were treated with sodium calcium EDTA-ate.

Using EDTA as anticoagulant, lead was determined in blood following trichloroacetic acid precipitation of the protein. The results, obtained by Berman's method, showed losses of up to $15 \%$ when compared with those obtained after dry ashing by a polarographic method. Subsequent analysis showed that after trichloroacetic acid precipitation the residual lead was in the protein precipitate and was not lost in later stages. Furthermore, an increase of EDTA concentration produced a higher loss of lead in the precipitate.

Various methods of protein precipitation were investigated but were found to be unsatisfactory. Perchloric acid (Neuberg, Strauss, and Lipkin, 1944) was, however, found to be satisfactory.

Materials and methods

Blood specimens

Ten millilitres of venous blood were collected with a 
disposable plastic syringe and emptied into a plastic blood bottle containing 10-20 mg disodium EDTA-ate.

\section{Atomic absorption spectrophotometry}

The photometer was a Perkin-Elmer model $303 \mathrm{fitted}$ with a Boling three-slot burner. The spectrophotometer was connected to a recorder readout and a Hitachi 165 recorder. An Intensitron lead hollow cathode lamp (6 $\mathrm{mA}$ current) was used. The instrument was set at $283.3 \mathrm{~nm}$, with a slit width of 4 scale units, with air pressure $30 \mathrm{lb} / \mathrm{sq}$ in and a flow setting of 9.0 scale units (about 24 litres $/ \mathrm{min}$ ), and with an acetylene pressure of 9.0 $\mathrm{lb} / \mathrm{sq}$ in and a flow setting of 5.0 scale units (about $2 \cdot 5$ litres $/ \mathrm{min}$ ).

A lean flame without traces of luminosity was used when aspirating the solvent. The aspiration rate for xylene was about $2-3 \mathrm{ml} / \mathrm{min}$, and the nebulizer was adjusted to give maximum absorption for a lead standard extracted into xylene. An arbitrary setting of noise suppression of 2 scale units and a scale expansion of 10 times was used.

Light scattering was measured at the non-absorbing lead ion line suppression of 2 scale units and a scale expansion of 10 times at $220 \cdot 3 \mathrm{~nm}$ and an absorbance of 0.004 was found for both samples and standards.

The dry ashing procedure with cathode ray polarography as described by Cernik (1967) was used for comparison.

\section{Perchloric acid precipitation}

Method Into a $150 \times 16 \mathrm{~mm}$ Pyrex test tube $4.0 \mathrm{ml}$ of well mixed blood were pipetted, followed by $6.0 \mathrm{ml}$ $2.0 \mathrm{M}$ perchloric acid, and mixed thoroughly with a fine glass rod for one minute. The mixture was allowed to stand and flocculate for 15 minutes, and was then centrifuged at $3000 \mathrm{rpm}$ for 10 minutes until the supernatant was clear (slight turbidity was unimportant). The supernatant was poured into a $100-\mathrm{ml}$ separating funnel containing $50 \mathrm{ml}$ water. Occasionally a button of precipitate covered the surface of the supernatant in the test tube. When this occurred, the button was held with a glass rod onto the side of the test tube whilst decanting. One millilitre of $2 \%$ ammonium pyrrolidine dithiocarbamate was added. The $p \mathrm{H}$ was adjusted to $2 \cdot 5-3.5$ with concentrated ammonia (s.g. 0.88). Xylene (Analar, $5.0 \mathrm{ml}$ ) was added and the lead complex was extracted into it by shaking for 90 seconds. The layers were allowed to separate. (When the shaking was firm but not vigorous little emulsification took place.) The xylene was centrifuged for 2-3 minutes at $3000 \mathrm{rpm}$. The clear organic supernatant was then analysed. The reagent blank was found by taking $6.0 \mathrm{ml}$ of $2 \mathrm{M}$ perchloric acid and $4.0 \mathrm{ml}$ of water through the procedure.

\section{Results}

\section{Choice of solvent for extraction}

The effect of solvents on the absorbance of lead has been investigated by Rooney (1968). When aspirating 20 ppm lead, absorbances for the ammonium pyrrolidine dithiocarbamate chelate in xylene, water, and methyl-iso-butylketone were $0.35,0.18$, and $\mathbf{0 . 2 6}$ respectively. Rooney considered xylene to be the best solvent. When the $p H$ was controlled during extraction, however, the optimum $p \mathrm{H}$ for extraction into xylene was close to that found for extraction into methyl-iso-butylketone by Willis (1961) and Selander and Cramér (1968a) and the absorbances were similar. The less soluble xylene is better because less is lost by dissolving in the aqueous phase.

Ammonium pyrrolidine dithiocarbamate concentration Willis (1961), Berman (1964), and Selander and Cramér $(1968 \mathrm{a}, \mathrm{b})$ found $1.0 \mathrm{ml}$ of $2 \%$ aqueous solution enough for lead extraction into methyliso-butylketone with 2 minutes' shaking. The extraction of lead into xylene does not differ in this respect except that the shaking time can be a minimum of 90 seconds.

\section{Concentrations of perchloric acid}

As in this method the perchloric acid had to ensure complete cleavage of lead from the protein, red cells, and EDTA chelate, a considerable excess was used. For instance, Neuberg et al. (1944) found that only $0.16 \mathrm{M}$ perchloric acid was required to precipitate the protein from a 1 in 10 dilution of defibrinated bovine blood, as shown by the filtrate giving a negative test for protein by the Biuret test. Duplicate samples from a pooled blood containing about $1 \mathrm{mg}$ EDTA per $\mathrm{ml}$ of blood were dry ashed and analysed by polarograph. Specimens of the same blood were also treated with different volumes of $1.0 \mathrm{M}$ and $2.0 \mathrm{M}$ perchloric acid, and the lead was determined after xylene extraction. At least $5 \mathrm{ml}$ of $2 \mathrm{M}$ perchloric acid were required for $4 \mathrm{ml}$ of blood.

\section{Standards and detection limits}

A calibration curve using lead standards extracted into xylene and measured at $283.3 \mathrm{~nm}$ showed that absorbance and concentration were linearly related. The absorbance corresponding to the detection limit is shown in the Figure and was equivalent to $5 \mu \mathrm{g}$ lead/100 ml blood.

\section{Comparison of cathode ray polarography with atomic absorption spectrophotometry}

Recoveries should not be tested on lead added to blood but on endogenous lead (Cernik, 1967; Selander and Cramér, 1968a,b) so that recoveries can only be tested by comparing the method under consideration with another accepted as standard, in this instance Cernik's (1967) method.

Thirty blood samples containing 20-100 $\mu \mathrm{g}$ lead/100 ml blood were analysed by both methods. They agreed within $0.5 \pm 3.96 \mu \mathrm{g} / 100 \mathrm{ml}$ (mean difference and standard deviation of the difference). The results by the two methods could be expressed 


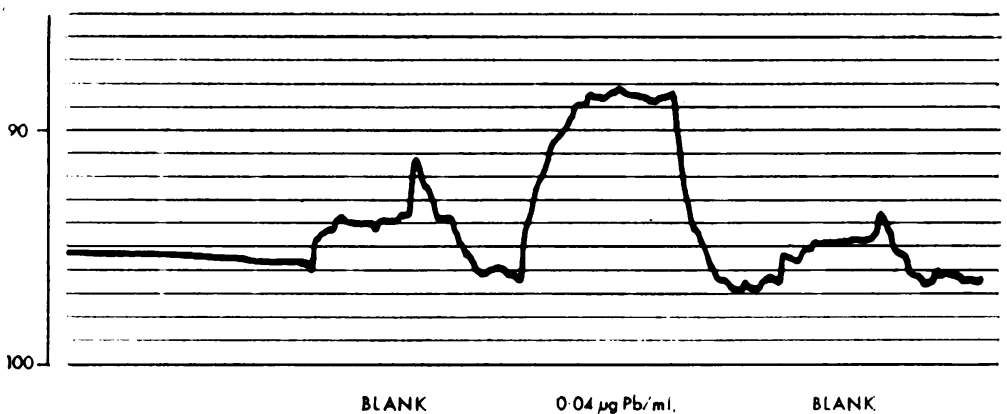

FIGURE Absorption traces for $0.04 \mu \mathrm{g} / \mathrm{ml}$ lead and blanks using instrument settings: scale expansion 10 and noise suppression 2. by the linear relationship: $\mu \mathrm{g}$ (new method) $=0.975$ $\times \mu \mathrm{g}$ (standard method) +1.035 .

The correlation coefficient was 0.985 .

\section{Effect of EDTA on recoveries of lead}

The possibility that $\left[\mathrm{H}^{+}\right]$concentration might play an important role was supported by an experiment using a heparinized blood in which $3.0 \mathrm{mg}$ EDTA $/ \mathrm{ml}$ blood was added before precipitating the protein with $10 \%$ trichloroacetic acid. Twentyone per cent of the lead was subsequently found in the precipitate, whereas all the lead was recovered when $2.0 \mathrm{M}$ perchloric acid was used as precipitant. When, however, the EDTA was added to the $10 \%$ trichloroacetic acid first, and then mixed with the blood, full recovery was obtained.

The lead was not co-precipitated. Aqueous lead standards containing approximately $1.0 \mathrm{mgEDTA} / \mathrm{ml}$ were determined by both the trichloroacetic acid and the perchloric acid methods. Eighty-two and 100 per cent recoveries were found respectively.

\section{Discussion}

With precipitation methods, the precipitant must convert the lead in the sample to a simple ionic form in addition to precipitating the proteins. Blood samples can contain EDTA either as an anticoagulant or as a result of therapy. The lead-EDTA chelate must be completely dissociated by the precipitant to yield ionic lead. It was found that $10 \%$ trichloroacetic acid was less satisfactory in releasing the lead than $2 \mathrm{~m}$ perchloric acid.

The chelation by EDTA requires the loss of four hydrogen ions from EDTA. It may therefore be possible for chelation to be reversed if the hydrogen ion concentration after protein precipitation is sufficient to displace the lead and reform EDTA. The low recoveries of lead after trichloroacetic acid treatment in the presence of EDTA observed by Berman (1964) and Slavin and Sprague (1964) and reported in this paper suggest that trichloroacetic acid, unlike the very much stronger perchloric acid, is unable to dissociate the lead-EDTA complex completely. Whether or not this is the explanation, the use of trichloroacetic acid for protein precipitation in analyses of lead in blood can lead to losses of up to $15 \%$ in the presence of EDTA. Perchloric acid ( $2 \mathrm{M})$ gave $100 \%$ recoveries, and is preferable for analyses of the blood of patients with lead poisoning who are being treated with EDTA and monitored by routine estimations of lead in blood.

I should like to thank Dr. M. H. P. Sayers for advice and encouragement, and Mr. H. T. Delves, The Institute for Child Health, for help with the statistical analysis.

\section{References}

Berman, E. (1964). The determination of lead in blood and urine by atomic absorption spectrophotometry. Atomic Absorption Newsletter, 3, 111-114.

Cernik, A. A. (1967). A dry ashing method for the determination of blood lead using cathode ray polarography. Brit. J. industr. Med., 24, 289-293.

Neuberg, C., Strauss, E., and Lipkin, L. E. (1944). Convenient method for deproteinization. Arch. Biochem. 4, 101-104.

Rooney, R. C. (1968). The determination of lead in blood and urine. World med. Electronics, 6, 138-142.

Selander, S., and Cramér, K. (1968a). Determination of lead in urine by atomic absorption spectrophotometry. Brit. J. industr. Med., 25, 139-143.

- , and - (1968b). Determination of lead in blood by atomic absorption spectrophotometry. Ibid. 25, 209-213.

Slavin, W., and Sprague, S. (1964). The determination of trace metals in blood and urine by atomic absorption spectrophotometry. Atomic Absorption Newsletter 3, 1-6.

Willis, J. B. (1961). Determination of lead in urine by atomic absorption spectroscopy. Nature (Lond.), 191, 381-382.

Received for publication June 26, 1969. 